\title{
Comparative Analysis on Speed Control of a Three Phase Induction Motor Drive Using Proportional Integral Differential and Scalar Closed Loop Fuzzy Logic Approach
}

\author{
Obinna Christopher Anyim, Joseph Michael Môm, Jonathan Uhaa Agber \\ Department of Electrical and Electronics Engineering, University of Agriculture, Makurdi, Nigeria \\ Email address: \\ jachrix07@gmail.com (O. C. Anyim), joe.môm@uam.edu.ng (J. M. Môm), juagber@uam.edu.ng (J. U. Agber) \\ To cite this article: \\ Obinna Christopher Anyim, Joseph Michael Môm, Jonathan Uhaa Agber. Comparative Analysis on Speed Control of a Three Phase \\ Induction Motor Drive Using Proportional Integral Differential and Scalar Closed Loop Fuzzy Logic Approach. American Journal of \\ Management Science and Engineering. Vol. 2, No. 5, 2017, pp. 123-131. doi: 10.11648/j.ajmse.20170205.16
}

Received: March 13, 2017; Accepted: April 12, 2017; Published: October 23, 2017

\begin{abstract}
The principles of controlling an AC driven three phase induction motor employing constant volts/hertz (v/f) control method and the space vector pulse width modulation (SVPWM) technique are reviewed. The induction motor is one of the most common electrical motors in usage, owing to its unique characteristics. Its further application strength requires a robust, problem handling, fast and intelligent speed control system. As a result of this, developing an intelligent knowledge based fuzzy logic controller (FLC) became eminent, and on this basis, this paper is presented. By varying the motor speed with input reference speed, an error signal and a feedback loop is generated. The FLC then operates on the principles of mapping with corrective measure of an error signal generated and it is regulated by sets of programmable IF-THEN rules integrating the Mamdani fuzzy inference approach. The rules projected and formed are used to overcome drawbacks such as complexities and insensitivities to changes in model parameters associated to conventional controllers. The application of the constant v/f method was used to maintain constant voltage to frequency ratio, therefore, creating a constant magnetic field and a maximum torque throughout the operating range. This in turn generates a voltage and an angle command for the actualization of the SVPWM technique. This entire set up was repeated but now with a classical control method like the proportional integral differential (PID) controller. With a simulation time of $2 \mathrm{~s}$, results showed that with FLC, a better speed response can be achieved from a $5 \mathrm{Hp} 350 \mathrm{~V} 50 \mathrm{~Hz}$ AC motor attaining steady-state at $0.21 \mathrm{~s}$ at no-load conditions. Simulation results showed a superior dynamic scheme of the FLC over the PI controller in terms of sensitivity to changes in model parameters. With a load torque of $10 \mathrm{Nm}$ applied at $1 \mathrm{~s}$, the FLC achieved stability at $1.2 \mathrm{~s}$ still maintaining a constant speed of $157 \mathrm{rads} / \mathrm{s}$.
\end{abstract}

Keywords: Three Phase AC Induction Motor Drive, Scalar Closed Loop, Fuzzy Logic Approach, SVPWM Technique

\section{Introduction}

Asynchronous motor otherwise called induction motor is known as one of the most commonly used electrical motor. It involves speed rotation of the magnetic field, in a rotary machine. It also depends upon the frequency and the number of poles of the machine. It is classified into two types namely; single and three-phase induction motor. An adjustable frequency alternating current (AC) drive system consists of an ordinary three-phase induction motor (IM), an adjustable frequency drive for speed control of the motor and an operators control station. The operator control station provides the operator with the necessary control information for starting and braking of the motor and also on varying the motor's speed.

The PID controller would have being an effective controller for not just speed control alone, if not for some complexities involved in individually controlling its respective controllers such as proportional, integral and derivative, and summing up their contributions to effectively yield controlled signal output. Also, for its insensitivity to changes made to model parameters which may be as a result of misrepresentation of some control variables. Therefore, the quest and concept of overcoming these drawbacks becomes eminent.

From the problems associated with classical controllers, 
there was a need to know how such individual control difficulties be effectively managed or totally substituted with a much more straight forward controller such as a fuzzy logic oriented one? Also, how can all the parameters involved in the control process be mathematically represented and dealt with to accommodate any form of changes made in their regards during operational periods to avoid any form of misrepresentation and insensitivity? In the same light, since this process is representing a closed loop or feedback loop, the question will then be its importance to the control process. With advancements in solid state power devices and microprocessors, variable speed induction motors powered by switching converters are increasingly recorded. These converters have the capability to regulate easily both the frequency and magnitude of the applied voltage and current to a given motor. This results to higher performance and efficiency. One of the common principles of this kind is known as the constant volts/hertz principle which concentrates mainly on varying the magnitude and frequency of the applied voltage to the stator winding, thereby maintaining a constant $\mathrm{v} / \mathrm{f}$ ratio. In so doing, the magnitude of the magnetic field is kept constant, thus, maintaining a constant maximum torque throughout the operating range. There are various classifications of the adjustable frequency AC drive based on the energy it delivers to a motor [5].

The PWM drive is employed because modulation is achieved by switching the states of the inverter and calculating the appropriate time period for each state. These achievements are possible due to the space vector transformation signals applied to the gates of the power transistors. PWM signals are pulse train with fixed frequency and magnitude plus variable pulse width. During the on and off intervals of the transistor, the PWM signal changes from one period to another as a result of its introduction to the gates [11]. In this control technique, the frequency of the PWM signal must be higher than the modulating signal, which is the fundamental frequency, in a way that the energy delivered to the motor and its load depends mostly on the modulating signal.

\section{Method}

In the industry today, amongst other types of machines, induction motors especially the squirrel cage has gained more popularity in terms of its numerous advantages ranging from its rugged construction and lower cost of maintenance to its reliability and better performance results etc. There are a host of methods available for speed control of this type of induction motor which includes; v/f control, field oriented control, flux vector control, sensor less vector control etc, but the $\mathrm{v} / \mathrm{f}$ control method happens to be common and simple to implement. This is because it takes speed reference command from an external source and varies it with the existing motor speed. This in turn creates a feedback loop and an error signal that is corrected by established rules incorporated in the fuzzy logic controller to generate a control signal used by other blocks to achieve the objectives of the control process.
By varying the voltage and frequency supply of the connected motor, the v/f control resultant are voltage magnitude and phase angle command for the realization of the SVPWM scheme which was adopted and used to obtain variable voltage and frequency from the voltage source inverter (VSI). This is then utilized by the connected three phase induction motor.

\subsection{Related Works}

[1] Presented a pulse width modulated AC drive technique. This review dealt with power conversion unit, PWM generation and its applications to the various types of control of AC drives including the $\mathrm{v} / \mathrm{f}$ control technique. [3] Presented a design model employing a Takagi-Sugeno fuzzy logic control scheme for controlling some of the parameters such as speed, torque, flux, voltage etc of an IM. Fuzzy logic based controllers were considered and a proposed rule based approach was presented. [4] Presented an intelligent and advanced speed control based on fuzzy logic technique to achieve maximum torque and efficiency. A rule based Mamdani type fuzzy logic controller was applied to a closed loop IM model. Scalar control method was used for controlling speed and a conventional PID was compared using MATLAB/SIMULINK. [6] Presented a v/f control of IM with different pulse width modulation techniques such as sine triangle pulse width modulation, third harmonic pulse width modulation (THPWM) and SVPWM using MATLAB/SIMULINK. The IM was modeled in the synchronous d-q reference frame. The performance of the IM on full load torque is compared using these techniques for third harmonic distortion, harmonic spectra, utilization of DC supply voltage, fundamental peak of the output voltage and motor speed. Results showed the superiority of SVPWM in performance characteristics. [2] Presented a comparative study of speed control of IM using PI and FLC. The IM was modeled using the $\mathrm{d}-\mathrm{q}$ axis. The $\mathrm{v} / \mathrm{f}$ control method was employed and a reference speed was set as the control architecture, which included a rule base of 49 rules. With regards to the FLC, these rules portray a nonchalant relationship between the two inputs which are speed error and its derivative and an output which is the change in control. [7] presented a rule-based FLC this was developed for speed control of a three-phase drive in a non-linear system. Speed control application was tested by conducting simulations under different operating conditions employing a constant v/f control scheme and SVPWM technique. The SVPWM was primarily used to generate gate signals for a three-phase two level inverter.

\subsection{The Fuzzy Logic Controller (FLC)}

The FLC is an intelligent controller that when well programmed, tends to emulates the thoughts of a human operator. As a means of a control law, it is described by a knowledge-based system consisting of IF-THEN rules with vague predicates and a fuzzy logic inference mechanism. The rule base is the main part of the FLC and it is formed by a 
family of logical rules that define the relationship between the two inputs (e and $\left.\delta_{\mathrm{e}}\right)$ and an output $\left(\mathrm{w}_{\mathrm{sl}}\right)$ of the controller. Therefore, its difference with the conventional controllers like the PID does not just lie in the type of logic, which can be Boolean or fuzzy, but in the intelligence and aspirations it renders through implementing human understanding in the control algorithm.

A typical FLC is defined by the relationship between change of control and the change in error at a given time (t) is expressed as;

$$
\begin{gathered}
w_{s l}=f\left(e(t), \delta_{e}(t)\right) \\
\delta_{e}(t)=e(t)-e(t-1)
\end{gathered}
$$

There are various steps taken when developing an intelligent controller based on fuzzy logic approach. They are;

i. Determining the process through the services of an expert operator and subsequently defining respective linguistic variables.

ii. Determining fuzzy sets through mapping.

iii. Constructing fuzzy rules covering the whole universe of discourse.

iv. Encoding fuzzy sets, rules and procedures to perform fuzzy inference into the expert system.

v. System evaluation and tuning, if necessary, to meet desired results.

\subsection{The Volt/Hertz, Block}

Assuming the voltage applied to a three-phase IM is sinusoidal, neglecting the stator voltage drop which is hardly $10 \%$ of the supplied voltage, then, at steady state, the terminal voltage $\mathrm{V}$ is proportional to $\omega \phi$.

Mathematically,

$$
\begin{gathered}
V^{*} \approx j \omega \phi^{*} \\
V \approx \omega \phi ;(\omega=2 \pi f)
\end{gathered}
$$

$V^{*}$ and $\phi^{*}$ are the phasors of the stator voltage and flux while $V$ and $\phi$ are their respective magnitudes (Zhenyu and
David 1998).

$$
\phi \approx \frac{V}{\omega}=\frac{V}{2 \pi f}=\frac{1}{2 \pi} * \frac{V}{f}
$$

From equation 5 , it follows that if the v/f ratio remains constant with changes in $\mathrm{f}$, then, $\phi$ remains constant too, leaving the torque independent on the supply frequency. In an ideal situation, the ratio between the magnitude and frequency of the stator voltage is usually based on the rated values of these variables or on the motor rating.

\subsection{The SVPWM Generator Block}

The space vector modulation is an addition to the primary PWM technique in the sense that it treats the inverter as a single unit. It is used for the creation of $\mathrm{AC}$ waveforms most common to three-phase AC powered motors at varying speeds from DC source using class D amplifiers. The inverter can be driven to eight unique states as a result of its switching vectors. The objective of the unique states is to generate PWM load line voltage that are averagely equal to a given or reference load line voltage. The objective is realized from each sampling period by properly selecting the switch states of the inverter and also calculating the appropriate time period for each state [6]. All these are realized by the space vector transformation technique.

The steps involved in achieving the state vector PWM technique can be implemented as follows [8]:

i. Determining $\mathrm{V}_{\mathrm{d}}, \mathrm{V}_{\mathrm{q}}, \mathrm{V}_{\text {ref }}$ and phase angle $\alpha$

ii. Then the time duration $\mathrm{T}_{1}, \mathrm{~T}_{2}$ and $\mathrm{T}_{0}$ during switching should be determined

iii. Lastly, determining the switching time of each transistor from switches S1 through S6.

\subsection{Block Diagram for Speed Control of Induction Motor}

The block diagram employing the speed control of induction motor is represented in figure 1. It depicts a scalar mode representation. The frequency and supplied voltage of the IM are varied such that it operates at steady state and at the desired speed. For scalar mode representation, both input and output commands are speed, unlike the vector control, where it is torque, flux and reference current respectively.

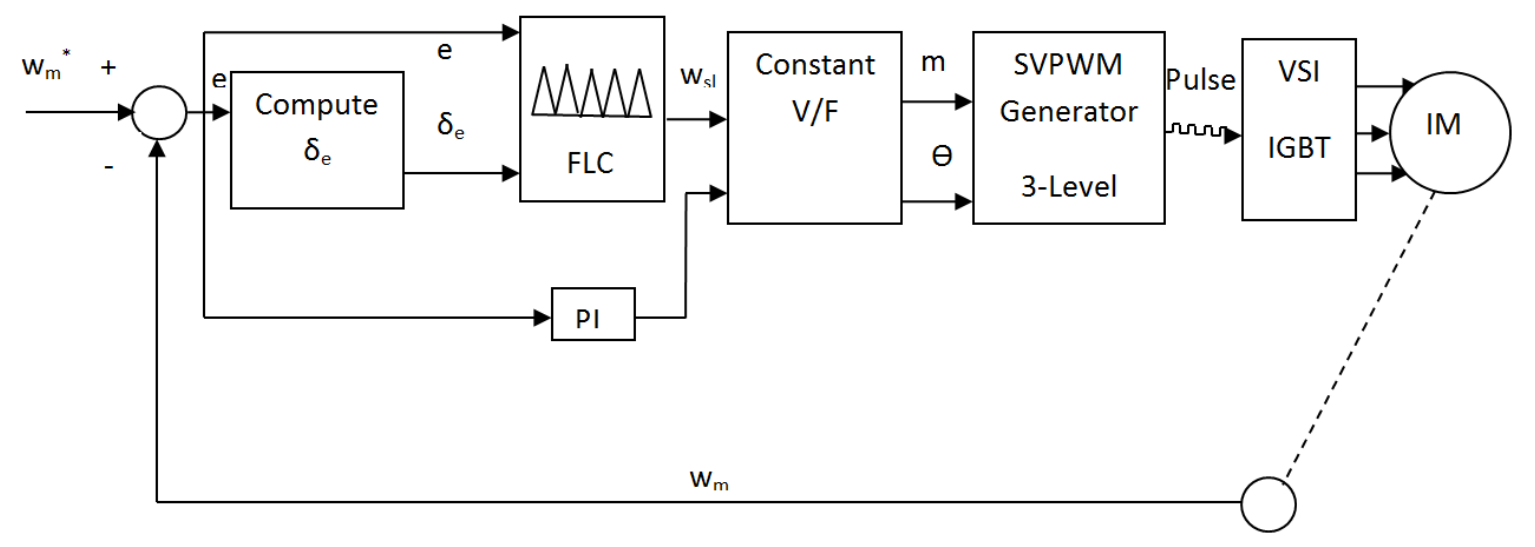

Figure 1. Block Diagram of a Volts/Hertz IM control with FLC Architecture. 
The input speed $\left(\mathrm{w}_{\mathrm{m}}{ }^{*}\right)$, is set as an external reference speed signal in figure 1 . This reference set point justifies the aim of this paper which is to control the speed of IM. The current speed of the IM is generated by a tacho-generator connected to the shaft of the motor. The generated motor speed $\left(\mathrm{w}_{\mathrm{m}}\right)$ is fed back and compared with the external reference speed $\left(\mathrm{w}_{\mathrm{m}}{ }^{*}\right)$ to create a speed control loop. This is called a feedback mechanism [9]. A feedback loop provides the quality of automation to the control system, where the information about the instantaneous state of the output motor speed is fed back to the input, in order to achieve a desired speed control.

The comparison and variation between the reference and the feedback motor speed generates a speed error (e). Its derivative is computed and both errors i.e. speed error (e) and change in error $\left(\delta_{\mathrm{e}}\right)$ serve as an input to the FLC. These inputs are processed by the various segmented blocks of the FLC, which comprise the fuzzifier, inference system (rule evaluation), aggregation of the rule output (composition) and the defuzzifier. The change of control $\left(\mathrm{w}_{\mathrm{sl}}\right)$ becomes the resultant output from the defuzzifier and the FLC as a whole. It in turn serves as an input to the $\mathrm{v} / \mathrm{f}$ controller block, which converts the current command to a constant $\mathrm{v} / \mathrm{f}$ ratio, thereby, generating a voltage $(\mathrm{m})$ and an angle magnitude $(\Theta)$ command. The angle tells the voltage where it should be with respect to the current. It, however, helps to determine the flux of the motor. By controlling this angle, low speed operation and torque control is improved [1]. Both magnitude and angle command serve as an input to a three-level SVPWM generator. The SVPWM generator block operates on the principle of mapping and it is used to generate switching vectors (pulses) corresponding to the actual sector and the optimum switching sequence of the three-level VSI. The VSI is essentially a power device with various switching on and off states that generates the proper root mean square (RMS) voltage level. A $350 \mathrm{~V}$
$50 \mathrm{~Hz}$ supply is used as an input source which is fed to the three phase controlled rectifier. The rectifier converts three phase AC supply to DC, which is then fed to the three phase inverter. The inverter converts DC supply to AC supply of desired magnitude and frequency and the output of the inverter is used as an input to the AC motor drive. The VSI uses the pulses from the SVPWM block to generate three-phase AC voltage whose frequency and amplitude can be varied by the FLC to produce the quadrature axis current reference $\mathrm{i}_{\mathrm{q}}{ }^{*}$ which in turn controls the motor torque and the direct axis current reference $\mathrm{i}_{\mathrm{d}}{ }^{*}$ which controls the motor flux. The corresponding DQ-ABC block in the modeled IM is used to convert $\mathrm{i}_{\mathrm{d}}{ }^{*}$ and $\mathrm{i}_{\mathrm{q}}{ }^{*}$ into current references, $\mathrm{i}_{\mathrm{a}}{ }^{*}, \mathrm{i}_{\mathrm{b}}{ }^{*}$, and $\mathrm{i}_{\mathrm{c}}{ }^{*}$ for current regulation. Current and voltage blocks provide their respective signals for visualization purpose. Motor current, voltage, flux, speed and electromagnetic torque signals are available at the output of the IM block. This same process is repeated but now with a PID controller and the speed error as its only input. The absence of the derivative of speed error adds to the advantages experienced when employing an intelligent controller such as the FLC for efficient and effective control. Results gotten after simulation were both compared and examined.

\section{Result}

The induction motor control model in figure 2 along with the various control technique and method has been designed and implemented using MATLAB/SIMULINK. It depicts the $\mathrm{v} / \mathrm{f}$ control of a closed loop three phase induction motor using the SVPWM technique which is fed to a VSI. For simulation, the values of control parameters are rated and represented in tables 1 through 3. An FLC was used to overcome the drawbacks already established in this paper which are peculiar to conventional controllers.

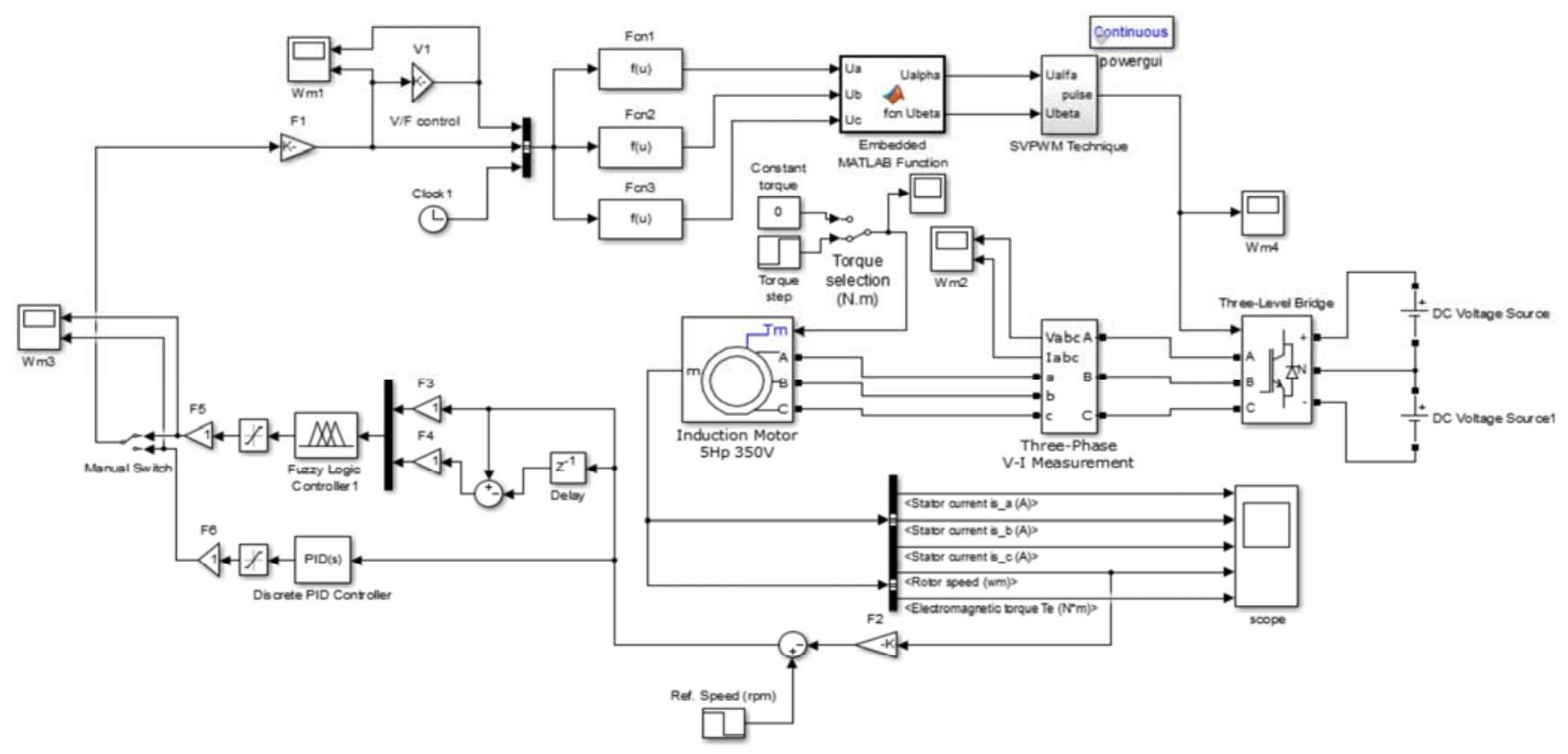

Figure 2. Scalar control model of an induction motor using fuzzy logic controller. 
Table 1. Parameters used in the 3- $\phi$ Induction Motor.

\begin{tabular}{ll}
\hline Asynchronous Motor (Mask) & \\
\hline Induction Motor Rating & {$[5 \mathrm{Hp}, 350 \mathrm{v}, 50 \mathrm{~Hz}]$} \\
Preset Model & No \\
Mechanical Load & Torque $\mathrm{T}_{\mathrm{m}}[10 \mathrm{Nm}]$ \\
Rotor Type & Squirrel Cage \\
Reference Frame & Stationary \\
Nominal Parameters & {$[5 * 746,350,50]$} \\
Stator Resistance /Inductance & {$[1.1150 .005974]$} \\
Rotor Resistance /Inductance & {$[1.0830 .005974]$} \\
Magnetizing Inductance $\mathrm{L}_{\mathrm{m}}$ & 0.2037 \\
Mechanical & {$[0.020 .0057522]$} \\
Initial Conditions & {$[1,0,0,0,0,0,0,0]$} \\
Unit & $\mathrm{SI}$ \\
$\mathrm{T}_{\mathrm{s}}$ Block & -1 \\
Iterative Model & Trapezoidal non-iterative \\
Number of Poles & 2 \\
Base Frequency & $2 * \pi * 50$ \\
\hline
\end{tabular}

Table 2. Parameters used in the PID Controller.

\begin{tabular}{ll}
\hline PI Controller (Mask) & \\
\hline Proportional Constant & 1 \\
Integral Constant & -1 \\
Derivative constant & 0 \\
Filter coefficient & 100 \\
\hline
\end{tabular}

Table 3. Parameters used in the IGBT Inverter.

\begin{tabular}{ll}
\hline IGBT Inverter, universal bridge (Mask) \\
\hline Arms & 3 \\
Snubber Resistance & 50 \\
Snubber Capacitance & $1 \mathrm{e}-6$ \\
Device & IGBT/Diodes \\
Ron & $0.2 \mathrm{e}-3$ \\
Forward Voltages & {$[21]$} \\
IGBT Parameters & {$[1 \mathrm{e}-6 \mathrm{e} \mathrm{e}-6]$} \\
Dc Voltage Source (Mask) & Source DC Voltage \\
Amplitude & $300 \mathrm{~V}$ \\
Measurements & All voltages and currents \\
\hline
\end{tabular}

\subsection{Simulation Results}

The results of simulating the IM model in SIMULINK of figure 2 for both FLC and PID controllers with no-load and load conditions are shown in figure 3 through 8 . From the simulation results obtained, comparisons were made and their differences noted and adequately explained.

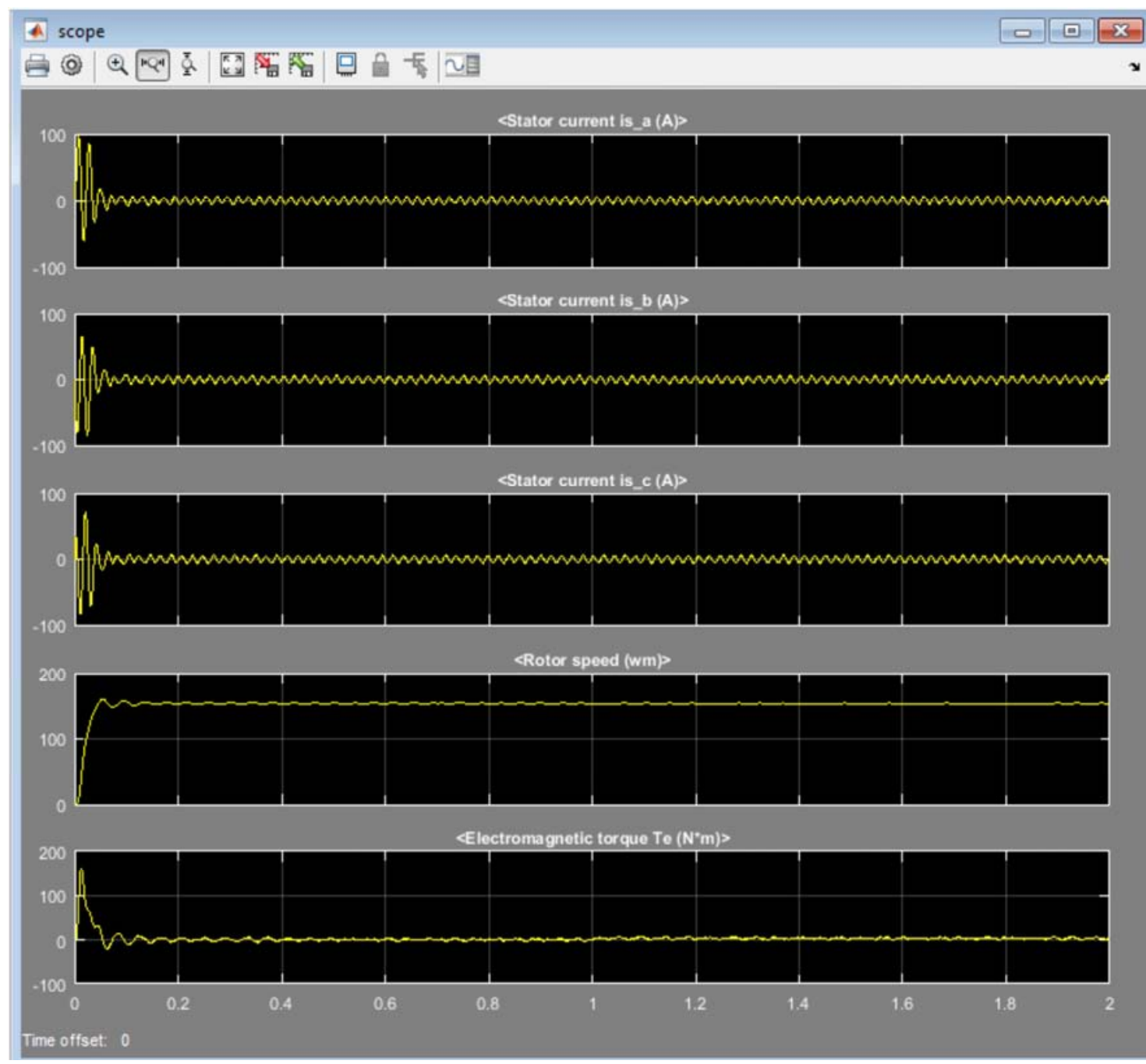

Figure 3. Iabc currents, rotor speed and electromagnetic torque Vs time plot on no-load and load using PID controller. 


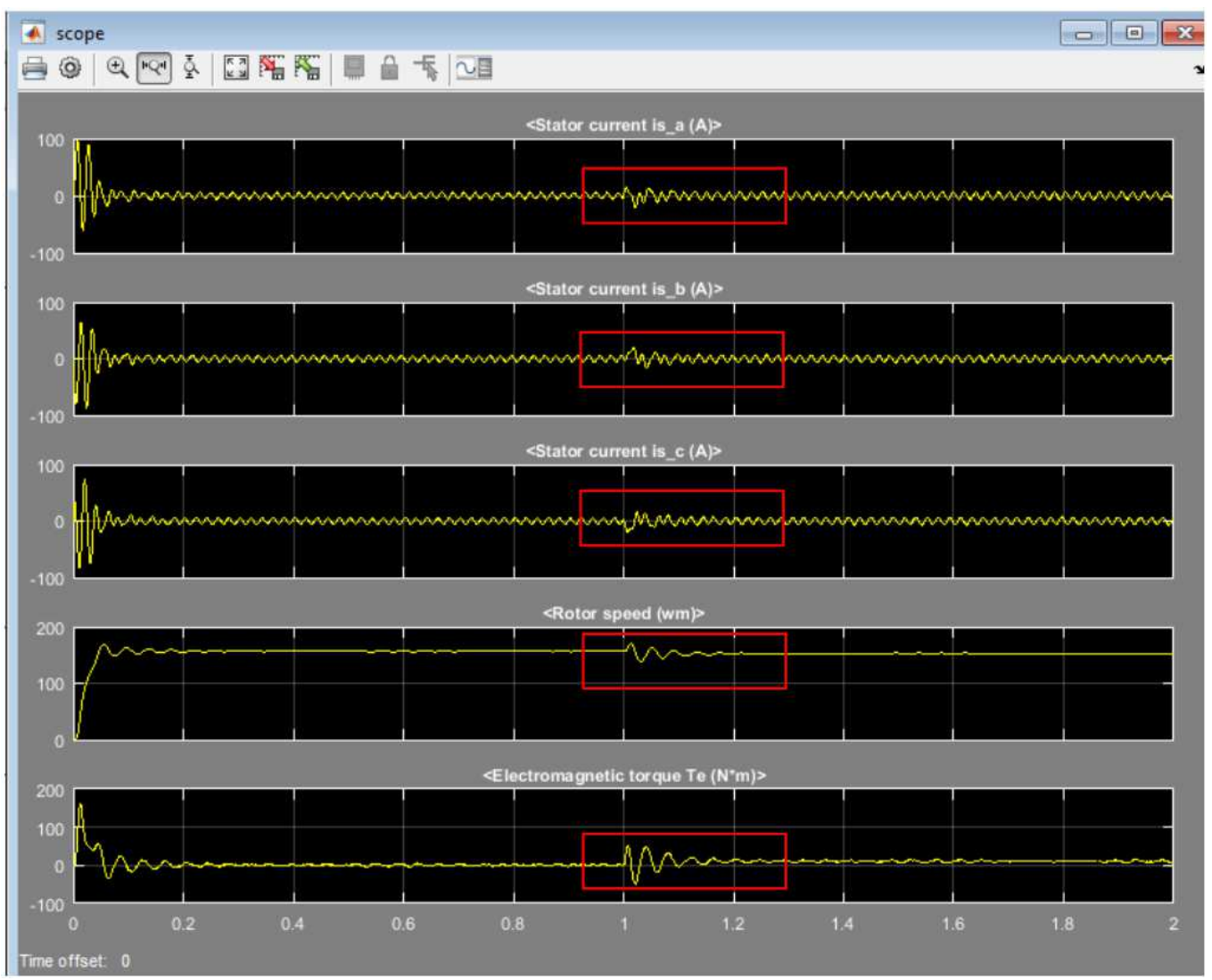

Figure 4. Iabc currents, rotor speed and electromagnetic torque Vs time plot on no-load and load using FLC.

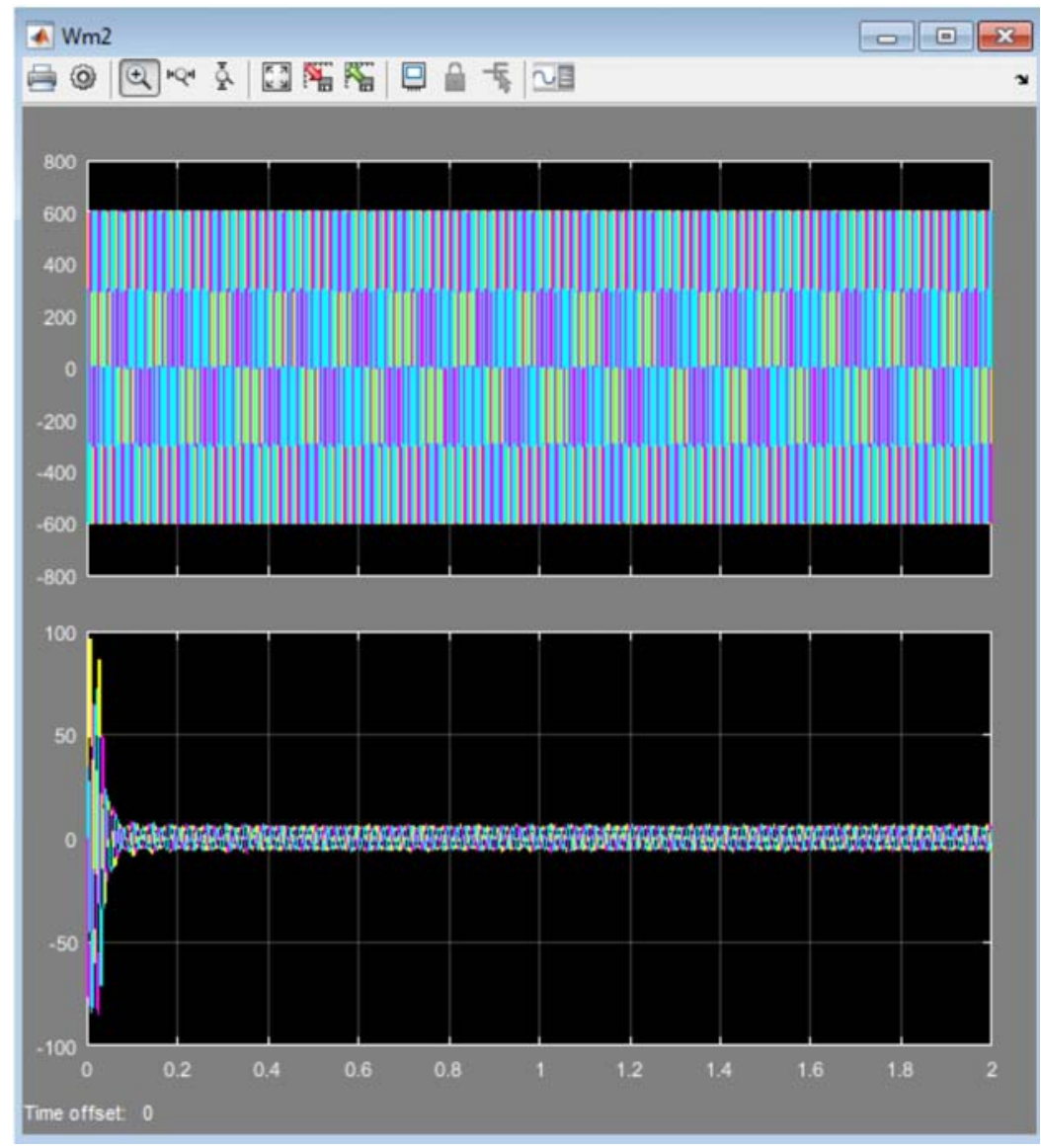

Figure 5. Voltage (above) and Multiplexed Stator Current (below) Vs time plot on no-load and load using PID controller. 


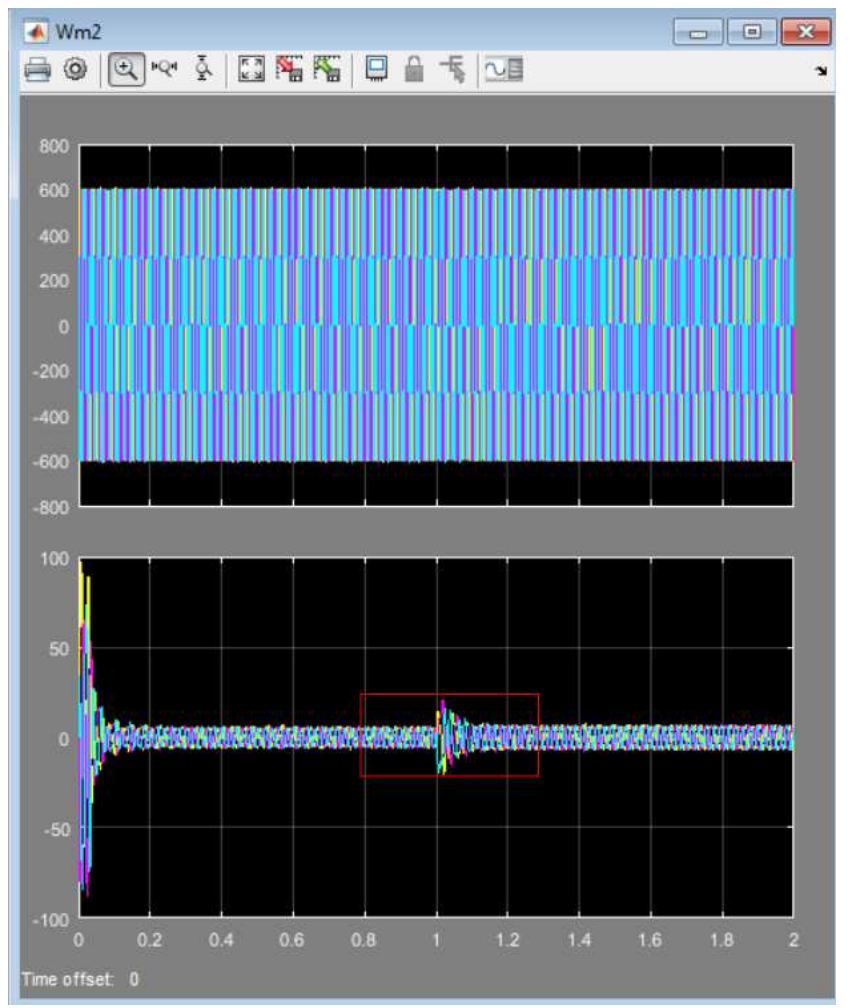

Figure 6. Voltage (above) and Multiplexed Stator Current (below) Vs time plot on no-load and load using FLC.

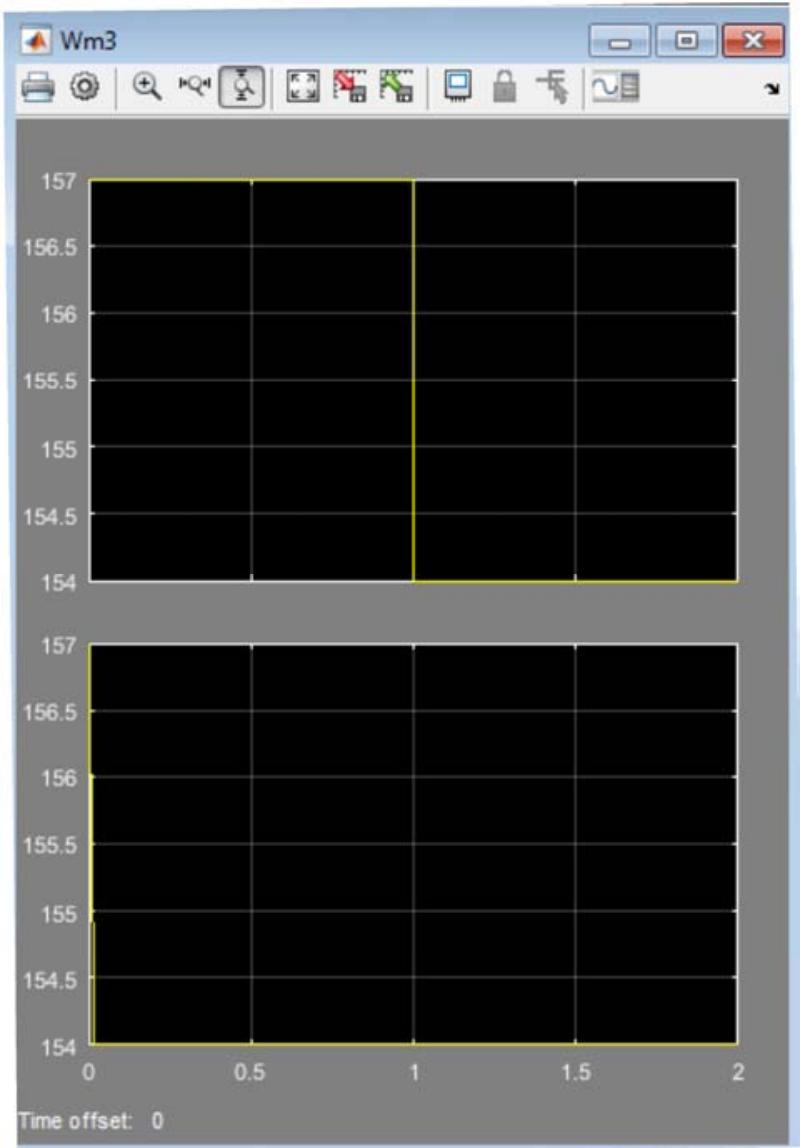

Figure 7. Output Signal for FLC (above) and PID (below) Controller respectively.

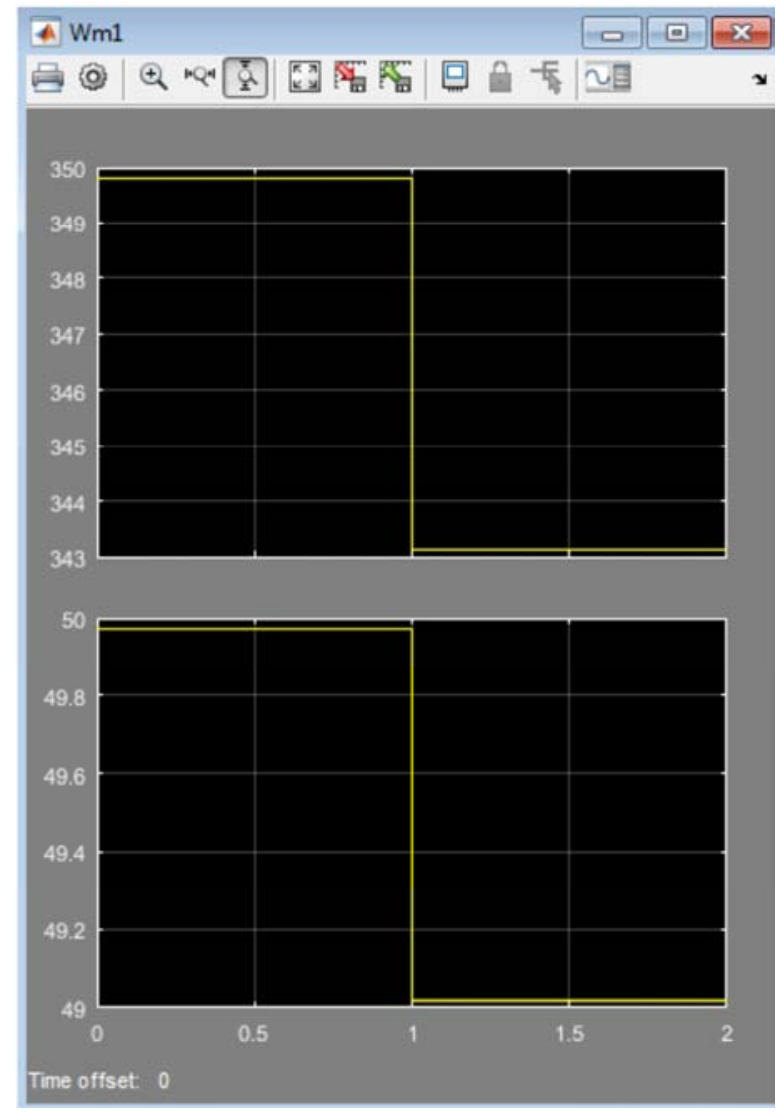

Figure 8. Output Signal for Voltage (above)/Frequency (below) Control using FLC Controller.

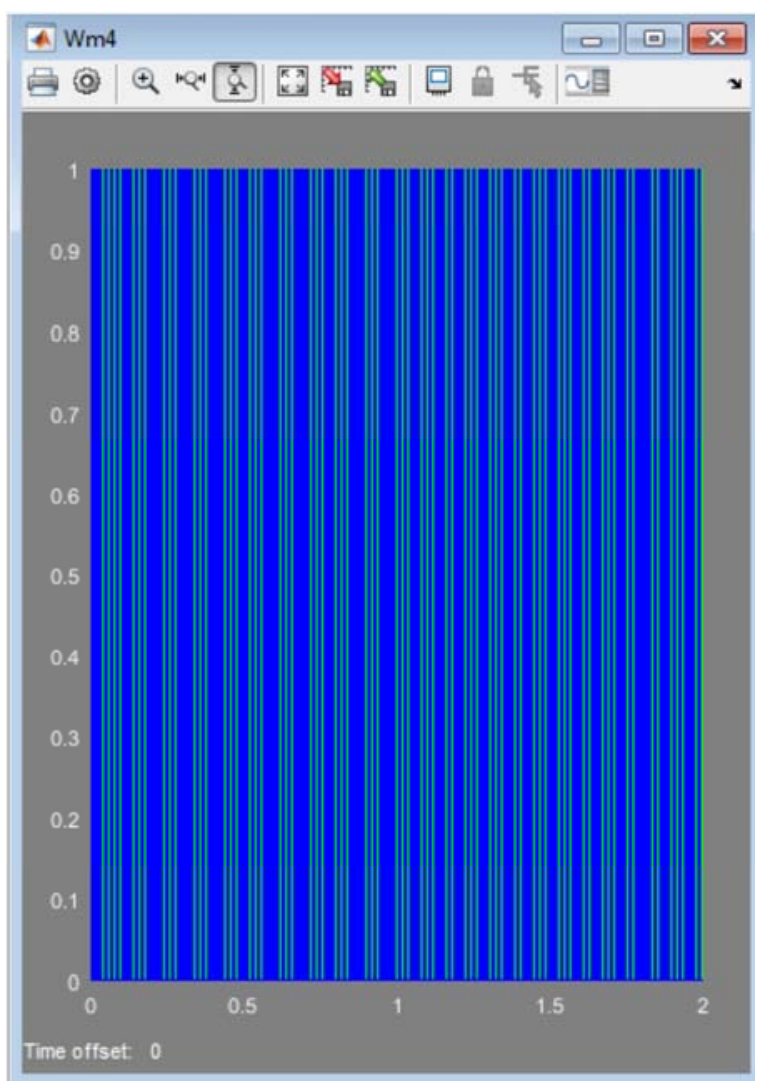

Figure 9. Pulse Signal for IGBT Inverter using FLC. 


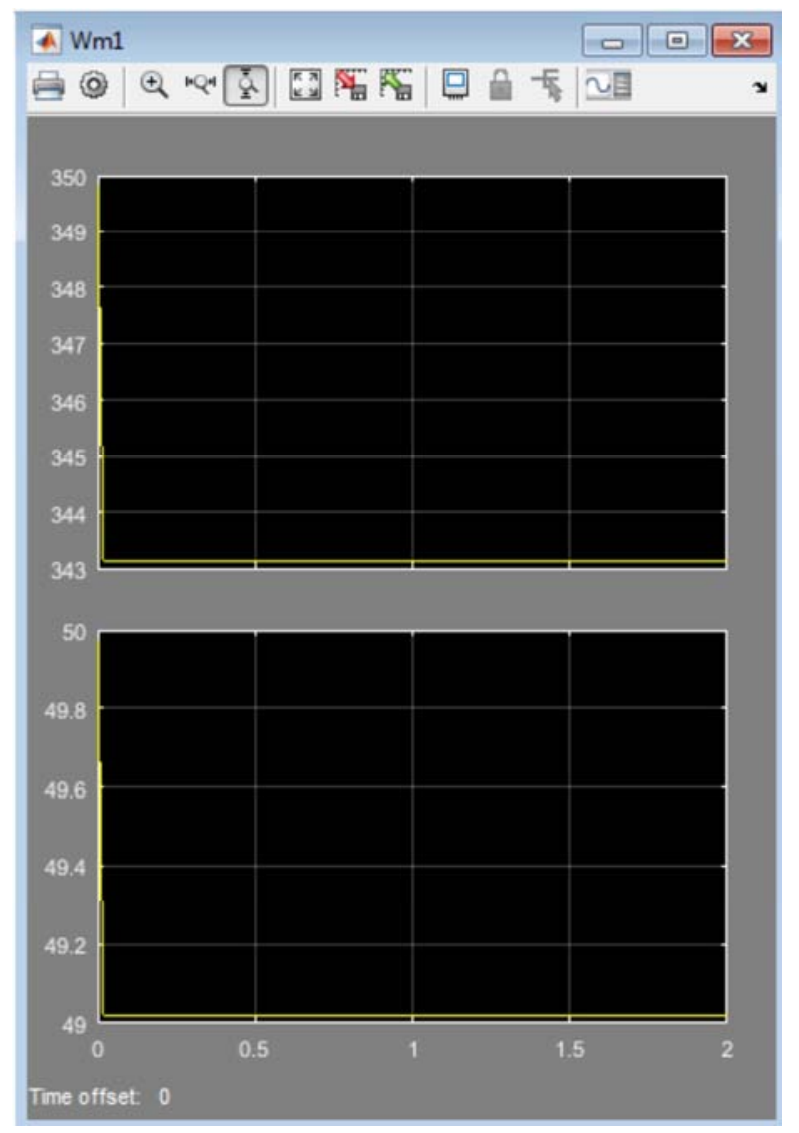

Figure 10. Output Signal for Voltage (above)/Frequency (below) Control using PID Controller.

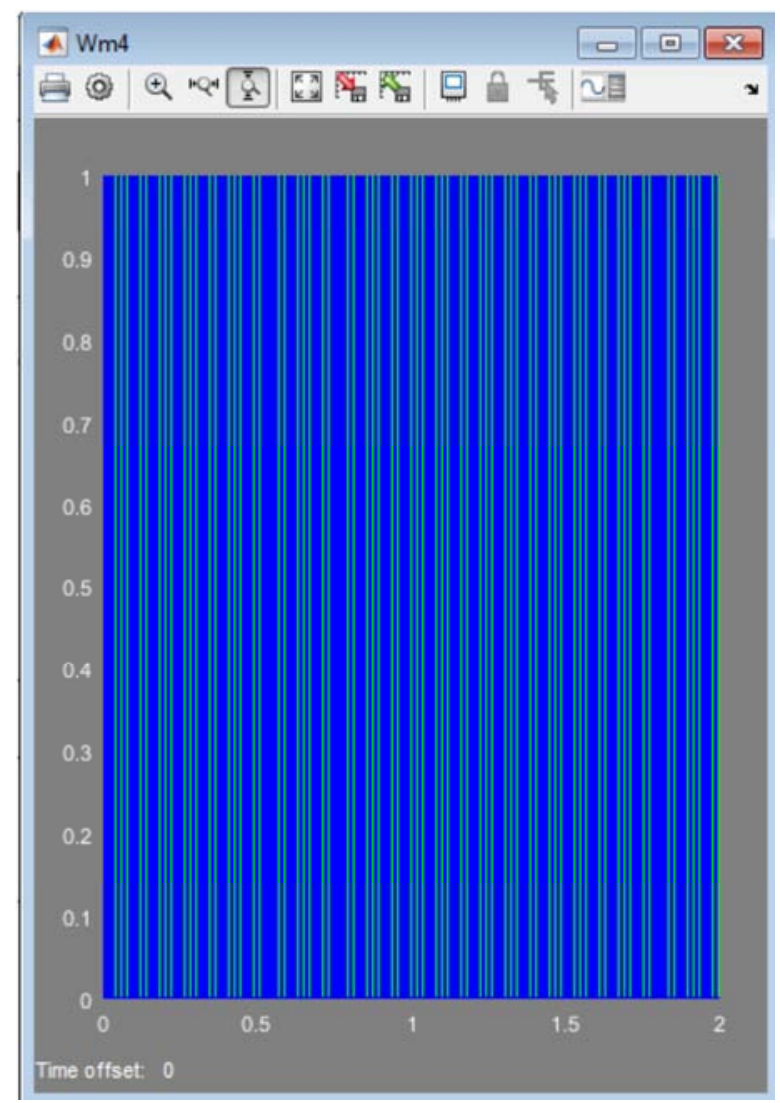

Figure 11. Pulse Signal for IGBT Inverter using PID Controller.

\section{Discussion}

The time of simulation was set at $2 \mathrm{~s}$. At the end of simulation, the scope represented in figure 3 shows the behavior of the controlled variables such as the respective Iabc stator currents, rotor speed and electromagnetic torque for no-load and load conditions, using PID controller. From the plot in figure 3, the IM draws a current of 90A during start-up with a starting torque oscillating around $157 \mathrm{Nm}$, having started from rest or zero speed. Similarly, the rotor speed increased marginally with regards to the starting torque until it reached a breakdown torque of $50 \mathrm{Nm}$ at $0.05 \mathrm{~s}$. Afterwards, it reached and maintained a constant value of $0 \mathrm{Nm}$ at $0.21 \mathrm{~s}$. This signifies a no-load condition, until it is acted upon by an applied torque value. At constant torque of $0 \mathrm{Nm}$, the rotor speed attained a steady-state of $157 \mathrm{rads} / \mathrm{s}$ at $0.15 \mathrm{~s}$ and maintains that till the end of the simulation.

Similarly, slightly different observations were recorded from figure 4 which represents the control employing the FLC. Comparing figures 3 and 4, at the time of $1 \mathrm{~s}$ when a load torque of $10 \mathrm{Nm}$ was applied, the electromagnetic torque is noticed to have oscillated from the no-load condition, to the tune of the applied torque in figure 4 whereas in figure 3 , no action was indicated to this effect. This also had corresponding effects on the rotor speed, the Iabc stator currents and its multiplexed form as in figure 6.

The distinction between the both controllers used, heaps praises on the FLC, owing to its sensitivity, effectiveness and efficiency in handling changes in model parameters. The authenticity of using a very well programmed FLC for speed control, especially in IM, can be verified from the quality of the output signal of the FLC, $\mathrm{v} / \mathrm{f}$ control and the pulse it delivers to the motor as in figure 7 , while 8 and 9 as compared to figures 10 and 11 respectively. This does not discredit the abilities of the PID controller especially in speed control, but provides a better and more reliable alternative to achieving satisfactory speed control response.

\section{Conclusion}

This paper presents an FLC used for controlling the speed of three-phase induction motor using a closed loop scalar approach. The entire closed loop speed control process is modeled and simulated using MATLAB/SIMULINK software. As a result of drawbacks peculiar to conventional controllers such as the complexities arising from individually controlling its respective controllers like proportional, integral and derivative and summing up their individual contributions to effectively yield controlled signal output. And also, for its insensitivity to changes made to model parameters which may be as a result of misrepresentation of some controller variables, creates the platform on which this paper is presented. With reference to speed and feedback, the FLC produces the proper control signal necessary for the various blocks to play their part in the whole control speed process of the connected motor. With confirmation from simulation results presented in the course of this paper, the 
FLC was able to address the problems raised by adequately managing cases of complexities, misrepresentation and insensitivity. This becomes an affirmation that the fuzzy logic approach is feasible and can be an interesting alternative to conventional control even when the system model is known. The controller gives maximum torque over the entire speed range. Therefore, in steady-state, the efficiency of the induction motor is also increased. In conclusion, the fuzzy logic controller shows fast response, smooth performance and high dynamic response with changing and transient conditions.

\section{References}

[1] Allen-Bradley (2000) 'Pulse Width Modulated (PWM) Drives'.

[2] Anmol Aggarwal, J. N. Rai, Maulik Kandpal (2015) 'Comparative Study of Speed Control of Induction Motor Using PI and Fuzzy Logic Controller'. IOSR Journal of Electrical and Electronics Engineering, Vol. 10, pp. 43-52.

[3] Ashok Kusagur, Dr. Kodad S. F., Dr. Sankarram B. V., (2005) 'Modelling of Induction Motor and Control of Speed Using Hybrid Controllers Technology'. Journal of Theoretical and applied information Technology.
[4] Divya Rai, Swati Sharma, Vijay Bhuria, (2012) 'Fuzzy Speed Controllers Design of 3- $\phi$ IM', ISSN 2250-2459, Vol. 2, Issue 5 pp. 145-149. International Journal of Emerging Technology and Advanced Engineering (IJETAE).

[5] Eaton Corporation, Cutler-Hammer (2008). 'AC Drive Theory and Applications'. Application Guide AP04014005E.

[6] Gaber El-Saady, El-Nobi A. Ibrahim, Mohamed Elbesealy, (2013) ' V/f Control of Three-phase IM drive with different PWM techniques', Innovative System Design and Engineering, Vol. 4, pp. 131-145.

[7] Jamal A. Ali, Mahammad A. Hannan and Azah Mohaned (2015) 'Rule-Based Fuzzy and V/f Control for IM Speed Response Using SVPWM Switching Technique'. Prezeglad Elektrotechniczny, pp. 133-136.

[8] Jin-Woo Jung and Ali Keyhani (2005) 'Space Vector PWM Inverter'. Mechatronic systems Laboratory, Dept. of Electrical and Computer Engineering, Ohio State University.

[9] Nagrath I. J. and Gopal M., (2007) 'Control Systems Engineering,' New Age International Publishers, Chap. 3.

[10] Priya Subhash Raichurkar and Asif Liyakat Jamadar (2015) 'V/f Speed Control of Three-phase IM Using Space Vector Modulation'. International Journal of Engineering Research and Technology (IJERT), Vol. 4.

[11] Zhenyu Yu and David Figoli (1998) 'DSP Digital Control System Applications'. Texas Instrument; SPRA284A. 